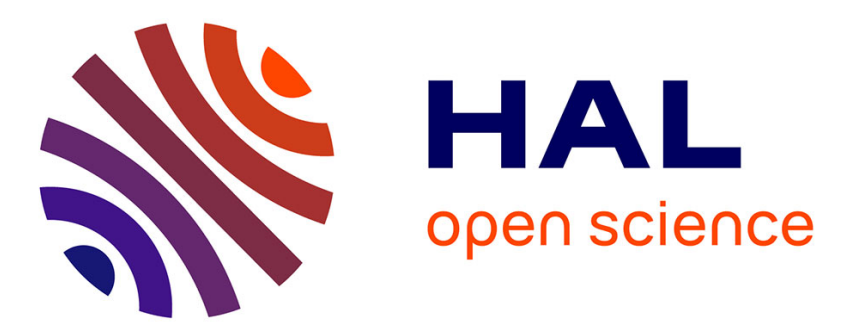

\title{
New formulae to evaluate the atmospheric layers of precipitable water and gases, applicable in solar radiation computing models
}

\author{
V. Badescu
}

\section{- To cite this version:}

V. Badescu. New formulae to evaluate the atmospheric layers of precipitable water and gases, applicable in solar radiation computing models. Revue de Physique Appliquée, 1988, 23 (12), pp.1869-1883. 10.1051/rphysap:0198800230120186900 . jpa-00246016

\section{HAL Id: jpa-00246016 https://hal.science/jpa-00246016}

Submitted on 1 Jan 1988

HAL is a multi-disciplinary open access archive for the deposit and dissemination of scientific research documents, whether they are published or not. The documents may come from teaching and research institutions in France or abroad, or from public or private research centers.
L'archive ouverte pluridisciplinaire HAL, est destinée au dépôt et à la diffusion de documents scientifiques de niveau recherche, publiés ou non, émanant des établissements d'enseignement et de recherche français ou étrangers, des laboratoires publics ou privés. 


\title{
New formulae to evaluate the atmospheric layers of precipitable water and gases, applicable in solar radiation computing models
}

\author{
V. Bădescu \\ Energetica, Centrale Electrice, Polytechn. Inst. of Bucarest, Bucarest 79590, Romania \\ (Reçu le 15 décembre 1986, révisé le 30 novembre 1987 et le 3 mai 1988, accepté le 30 août 1988)
}

\begin{abstract}
Résumé. - Les formules proposées utilisent les valeurs de la pression atmosphérique, de la température et de l'humidité relative, paramètres mesurés dans de nombreuses stations météorologiques. Les résultats sont en bonne corcordance avec ceux obtenus en utilisant certaines formules empiriques proposées par d'autres auteurs. Pour un calcul plus exact de la couche d'eau précipitable, nous avons établi une relation plus générale que les corrections empiriques déjà existantes. La théorie a été comparée avec les résultats obtenus en utilisant six modèles atmosphériques. Une bonne concordance a été trouvée.
\end{abstract}

\begin{abstract}
The theoretical formulae we propose use the ground values of air pressure, temperature and relative humidity, parameters measured by most of the meteorological stations. The results were found to be in good agreement with those obtained from several semi-empirical formulae proposed by other authors. To compute more exactly the precipitable water layer it was established a relation which is more general than the existing empirical corrections. The theory was compared with the results obtained by using six atmospheric models based on measurements. It was found out a good concordance.
\end{abstract}

\section{Introduction.}

The efficient utilization of solar energy requires to know the temporal and spatial variation of solar irradiance. In this context, the relatively low density of solar radiation recording stations favoured the calculation procedures, with the main purpose to provide estimations for the locations missing actinometric measurements. Reviews and classifications of the main calculations procedures of solar radiation have been recently made by May, Collingbourne and McKay [1], Bener [2] and Davies [3].

Most of computing models take into account the effects that gases and precipitable water have on atmospheric attenuation of solar radiation. Evaluation of precipitable water or gases amount is difficult because of their complex dependence on atmospheric state. This was the main reason which led to the application of some semi-empirical formulae, such as those proposed by Hann [4], Paltridge and Platt [5], Gates [6], Smith [7] to compute precipitable water thickness. The above formulae are generally incomplete and the authors do not present theoretical justifications and limits of validity.

The present paper intends to reach two main purposes. Firstly, we elaborated a simple theoretical model to estimate the amount of precipitable water and gases from the atmosphere. For higher accuracy the model took into account the effects of the main atmospheric parameters. Secondly, we elaborated procedures for routine computations. In the last case we created two facilities. (i) Our results have been condensed in analytical formulae obtained by a least square method or interpolation. (ii) Formulae depend only on the ground level values of the atmospheric parameters which are supplied by most meteorological stations.

\section{Homogeneous equivalent layers of precipitable water and gases.}

We considered a vertical cylindrical column of $H$ height, section $S$, which has its base at altitude $h^{*}$. The total water vapour mass, $m_{\mathrm{w}}$, and the total mass of any gas $i, m_{g i}$, which exist in this column are given by (Appendix A) :

$$
\begin{aligned}
& m_{\mathrm{w}}=\frac{S}{R_{\mathrm{w}}} \int_{h^{*}}^{H} \frac{A w(h)}{1+A w(h)} \frac{p(h)}{T(h)} \mathrm{d} h \\
& m_{g i}=\frac{S}{R_{i}} \int_{h^{*}}^{H} \frac{\kappa_{i}(h)}{1+A w(h)} \frac{p(h)}{T(h)} \mathrm{d} h
\end{aligned}
$$


where $\kappa_{i}(h), w(h), p(h), T(h)$ are the values at altitude $h$ of volumic fraction of gas $i$, humidity content, pressure and temperature, respectively, $R_{\mathrm{w}}$ and $R_{i}$ are the constant of perfect gases per unit mass of water vapour and gas $i$, respectively, and $A$ is a constant (see Appendix A).

To compute the integrals from (1) we used vertical profiles of temperature and humidity content obtained by statistic averaging of measurements. We accept the variation $T(h)$ corresponding to the TSA60 atmospheric model, which is the linearised version of the international model CIRA-61 [8]. We considered the superior limit of the atmosphere as being $H=55 \mathrm{~km}$. At this altitude the atmospheric density is over 2000 times lower than at sea level and the neglected quantity of air is about $0.08 \%$ of the whole quantity of air from the atmosphere [8]. The TSA-60 model considers the atmosphere shared in four thermal regions : (1) the troposphere, having the upper limit $h_{1}$, with linear decreasing of temperature, (2) the tropopause (upper limit $h_{2}$ ) with constant temperature, (3) the stratosphere (upper limit $h_{3}$ ) with linear increasing of temperature, (4) the stratopause (upper limit $h_{4}=H$ ), with constant temperature. Consequently, the vertical profile of $T(h)$ is :

$T(h)= \begin{cases}T^{*}-a_{1}\left(h^{*}-h\right) & {\left[h^{*}, h_{1}\right]} \\ T^{*}-a_{1}\left(h^{*}-h_{1}\right)=T_{\mathrm{t}}=\text { Cst. } & \left(h_{1}, h_{2}\right] \\ T_{t}-a_{3}\left(h_{2}-h\right) & {\left[h_{2}, h_{3}\right]} \\ T_{t}-a_{3}\left(h_{2}-h_{3}\right)=T_{\mathrm{s}}=\text { Cst. } & \left(h_{3}, h_{4}\right]\end{cases}$

In (2) $T^{*}$ is atmospheric temperature at ground level. Also, $a_{1}$ and $a_{3}$ are the coefficients of altitudinal variation of temperature in troposphere and stratosphere, respectively. According to the TSA-60 model the values of the constants from (2) are : $h_{1}=11 \mathrm{~km}, \quad h_{2}=25 \mathrm{~km}, \quad h_{3}=45 \mathrm{~km}, \quad a_{1}=$ $-0.0065 \mathrm{~K} / \mathrm{m}, a_{3}=0.0027 \mathrm{~K} / \mathrm{m}$.

We accepted for the humidity content the expression proposed by Smith as a result of measurements [7] :

$$
w(h)=w^{*}\left[\frac{p(h)}{p^{*}}\right]^{\alpha}
$$

where $w^{*}$ and $p^{*}$ are the parameter values at ground level. The average value of $\alpha$ on USA territory is 3 $[7,9]$. We considered this value corresponding to the standard profile of $w$. We expect equation (3) to be more reliable in clear air, when present clouds do not influence the monotonously decreasing distribution of $w$.

Pressure vertical distribution in a wet statical atmosphere is given by (Appendix B) :

$$
\frac{\mathrm{d} p}{p}=-\frac{g}{R_{\mathrm{a}}} \frac{1+w}{1+A w} \frac{\mathrm{d} h}{T}
$$

where $g$ is the gravitational acceleration at altitude $h$.
Equation (4) is a generalization of the Laplace equation [8], which is valid only for dry air. In case the humidity content has the expression (3), the solution of equation (4) is (Appendix B) :

$$
p(h)=p^{*}\left(1-\frac{\beta w^{*} F^{\alpha}}{1+(\alpha+1) \beta w^{*} F^{\alpha}}\right) F
$$

where :

$$
F=\exp \left(D-\int_{h^{*}}^{h} \frac{g}{R_{\mathrm{a}}} \frac{\mathrm{d} h}{T}\right) .
$$

The expressions of $D$ and $\beta$ can be found in Appendix B while $R_{\mathrm{a}}$ is the constant of perfect gases per unit mass of dry air.

If in (6) we use the vertical profile (2) of $T(h)$, the function $p(h)$ may be expressed as :

$$
p(h)=p^{*} \phi_{k}\left(h, h^{*}, T^{*}, w^{*}\right) .
$$

Deduction of equation (7) and the expressions of the functions $\phi_{k}$ can be found in Appendix C.

Introducing (2), (3), (7) in (1) we obtain the precipitable water thickness, $h_{\mathrm{w}}$, and the thickness of an equivalent homogeneous layer from the gas $i$, $h_{g i}$ :

$$
\begin{gathered}
h_{\mathrm{w}}=\frac{A p^{*} \theta_{\mathrm{w}}\left(T^{*}, w^{*}\right)}{R_{\overline{\mathrm{w}}} \rho_{\mathrm{w}}\left(T^{*}\right)} \\
h_{g i}=\kappa_{i} T^{*} \theta_{g i}\left(p^{*}, T^{*}, w^{*}\right) .
\end{gathered}
$$

In (8) $\rho_{\overline{\mathrm{w}}}\left(T^{*}\right)$ is water density at temperature $T^{*}$. Deduction of equation (8) and the expressions of the functions $\theta_{g i}, \theta_{\mathrm{w}}$ can be found in Appendix D.

To facilitate routine computations of $h_{g i}$ and $h_{\mathrm{w}}$ we determined the values of the functions $\theta_{\mathrm{w}}, \theta_{g i}$ for a large amount of ground level values of the atmospheric parameters. Many measurements stations do not report the humidity content $w^{*}$ but the relative humidity $u^{*}$. The usual relation between the two values is $[10]$ :

$$
w^{*}=0.622 u^{*} \frac{p_{\mathrm{vs}}\left(T^{*}\right)}{p^{*}-u^{*} p_{\mathrm{vs}}\left(T^{*}\right)}
$$

where $p_{\mathrm{vs}}\left(T^{*}\right)$ is the pressure of saturated water vapour at temperature $T^{*}$.

For any realistic values of $u^{*}$ and $T^{*}$ the product $u^{*} \cdot p_{\mathrm{vs}}$ is small compared to $p^{*}$. Then $w^{*}$ has a variation almost proportional to $1 / p^{*}$. Consequently, in case we choose the relative humidity $u^{*}$ as a thermodynamic parameter the functions $\theta_{\mathrm{w}}$ and $\theta_{g i}$ also depend on the atmospheric pressure.

In case of $\theta_{g i}$ the results were fitted by a least square method, using the following regression function :

$$
\begin{aligned}
\theta_{g i}=d_{0}+d_{1} & T^{*}+d_{2} p^{*}+d_{3} u^{*}+ \\
& +d_{4}\left(T^{*}\right)^{2}+d_{5}\left(p^{*}\right)^{2}+d_{6}\left(u^{*}\right)^{2}
\end{aligned}
$$


where the units are : $T^{*}(\mathrm{~K}), p^{*}(\mathrm{hPa}), u^{*}$ (nondimensional, underunitary).

Table I contains the values of the coefficients $d_{j}(j=0,6)$ for several altitudes $h^{*}$, together with the maximum error for a given domain of $T^{*}$ and $p^{*}$.

Figure 1 shows the dependence of $\theta_{\mathrm{w}}$ on pressure, at constant $u^{*}$, for two altitudes and several temperatures. The pressure influence is reduced and almost linear. For a given temperature the slope of $\theta_{\mathrm{w}}$ variation slightly depends on altitude. This slope becomes more abrupt with increasing temperature. For the same temperature, the dependence of $\theta_{\mathrm{w}}$ on $p^{*}$ increases in case of higher altitudes. The function $\theta_{\mathrm{w}}$ strongly depends on temperature. This dependence decreases with increasing pressure, a fact which is more evident in case of high tempera-

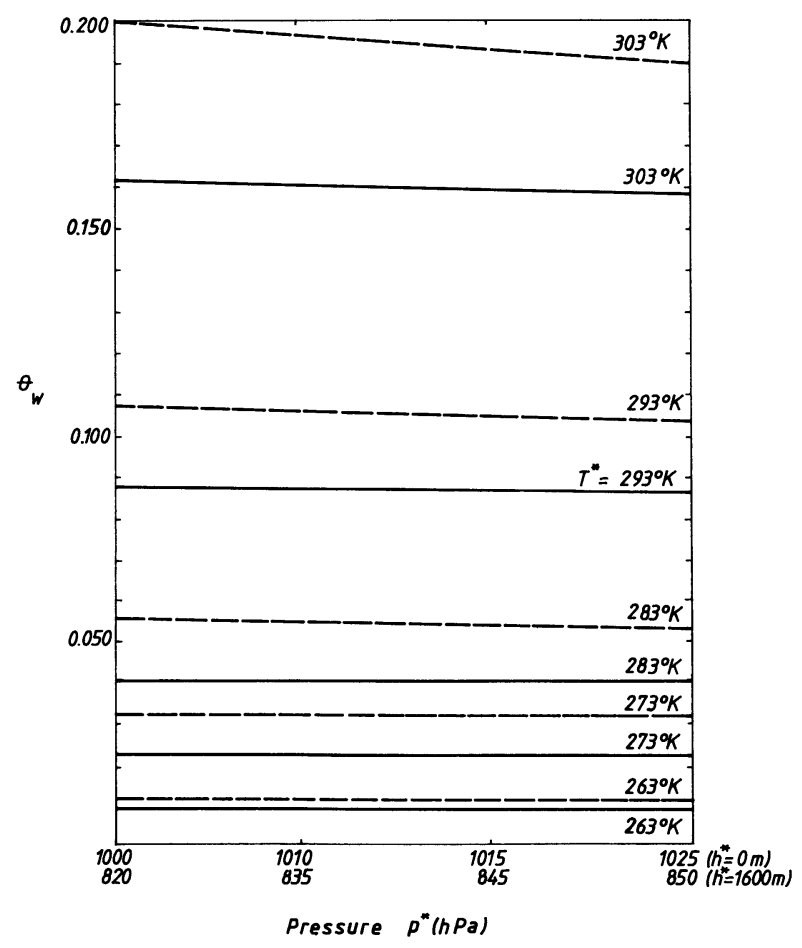

Fig. 1. - The dependence of $\theta_{w}$ on pressure for two ground level altitudes : $h^{*}=0 \mathrm{~m}$ (continuous line) and $h^{*}=1600 \mathrm{~m}$ (non-continuous line). tures. Also, $\theta_{w}$ dependence on temperature increases with the altitude of location.

The considerations mentioned above determined us to choose after several tests the following interpolation function :

$$
\theta_{\mathrm{w}}=u^{*}\left(\frac{p_{\mathrm{sup}}}{p^{*}}\right)^{m} \sum_{j=0}^{5} c_{j}\left(\tau^{*}\right)^{j}
$$

where the units are the same as in equation (10). In (11) $p_{\text {sup }}$ is the higher limit of the pressure interpolation interval and $\tau^{*}=T^{*} / 288.16$. The optimum value of $m$ varies between 0.92 and 0.97 by decreasing the temperature from $303 \mathrm{~K}$ to $263 \mathrm{~K}$. $m=0.95$ is a good average value.

Table II contains the values $c_{j}(j=0,5)$ for several altitudes and the maximum error for each interval of validity.

Figure 2 shows the dependence of the precipitable water thickness upon temperature, determined with equation (8a) and respectively by means of certain formulae proposed or used by Hann [4], Barbaro et al. [11], Paltridge and Platt [5], Gates [6], Smith [7]. The calculations have been performed at constant $p^{*}$ and $u^{*}$ and using $\alpha=3$ in equation (3). Figure 3 shows the deviations between the values computed with the existing formulae and equation (8a), respectively. The relation we proposed is in good agreement with the quoted formulae, excepting Hann's earlier relation. Compared with our model, the other models estimate lower values of precipitable water. A partial explanation follows. Most existing models use data only from the atmospheric layer between $1000-500 \mathrm{hPa}(0-5 \ldots$ $6 \mathrm{~km}$ ). Figure 4 shows the ratio between the thickness of precipitable water from the atmospheric layer of $h$ height above sea level, $h_{\mathrm{w}(0-h)}$, and the total precipitable water from the atmosphere, $h_{\mathrm{w}(0-H)}$. By neglecting the humidity above $5 \mathrm{~km}$ altitude one underestimates the precipitable water thickness by 5 to $10 \%$. The precipitable water above $11 \mathrm{~km}$ altitude is less than $0.3 \%$ from the total atmospheric precipitable water.

Some authors consider the thickness of precipitable water cannot be correctly estimated using values measured at ground level [12]. But it is

Table I. - The values of the coefficients $d_{j}$ from equation (10) and their interval of validity, for several altitudes $h^{*}$. E- maximum error of equation (10).

\begin{tabular}{|c|c|c|c|c|c|c|c|c|c|c|}
\hline $\begin{array}{l}h^{*} \\
(\mathrm{~m})\end{array}$ & D0 & D1 & D2 & D3 & $\mathrm{D} 4 * 10000$ & D5* 10000 & D6* 10000 & $\begin{array}{c}E \\
(\%)\end{array}$ & $\begin{array}{l}\text { Temp. } \\
\text { (K) }\end{array}$ & $\begin{array}{l}\text { Pres. } \\
\text { (hPa) }\end{array}$ \\
\hline 0 & 85.044210 & 00000080 & -0.1021056 & 0.0781151 & 0.5478409 & 0.5040189 & 88878 & 0.25 & $263-313$ & $1000-1025$ \\
\hline 1000 & 49.410600 & -0.0174469 & -0.0396459 & 0.0620983 & 53 & 0.2200148 & 0.0738825 & -0.19 & $258-308$ & $890-910$ \\
\hline 2000 & 39.742053 & -0.0133595 & -0.0225560 & 0.0485225 & 0.2539830 & 0.1448931 & -0.0409412 & 0.11 & $253-303$ & $780-820$ \\
\hline 3000 & 35.158843 & -0.0153909 & -0.0110516 & 0.0527759 & 0.2897178 & 0.0786069 & -0.0667994 & 0.16 & $253-303$ & $680-720$ \\
\hline 4000 & 34.541907 & -0.0155604 & -0.0104860 & 0.0563959 & 0.2913237 & 0.0848034 & -0.0797574 & 0.17 & $253-303$ & $595-635$ \\
\hline
\end{tabular}


Table II. - The values of the coefficients $c_{j}$ from equation (11) and their interval of validity, for several altitudes $h^{*}$. E - maximum error of equation (11).

The direct application of the interpolation method for the standard model at $h^{*}=0 \mathrm{~m}$ do not assure the continuity of $c_{j}$ for $\alpha=2.5,3$ and 3.5 (see also Tab. III). The coefficients we present here for this altitude were computed by using a quasi-standard atmospheric model, which has the tropopause height $h_{2}=29 \mathrm{~km}$. In the body of the text we showed that no influence of $h_{2}$ on the values of $\theta_{\mathrm{w}}$ was observed.

\begin{tabular}{|c|c|c|c|c|c|c|c|c|c|}
\hline $\begin{array}{l}h^{*} \\
(\mathrm{~m})\end{array}$ & $\mathrm{CO}$ & $\mathrm{C} 1$ & $\mathrm{C} 2$ & $\mathrm{C} 3$ & $\mathrm{C} 4$ & C5 & $\begin{array}{c}E \\
(\%)\end{array}$ & $\begin{array}{c}\text { Temp. } \\
\text { (K) }\end{array}$ & $\begin{array}{l}\text { Pres. } \\
(\mathrm{hPa})\end{array}$ \\
\hline 0 & 1877.5078 & - 9377.0664 & 18674.2380 & -18526.9690 & 9150.9141 & - 1798.5491 & 2.9 & $263-313$ & $1000-1025$ \\
\hline 300 & 1978.6953 & - 9882.3242 & 19680.7380 & -19526.5000 & 9645.5430 & -1896.0718 & 4.9 & $263-313$ & $970-995$ \\
\hline 600 & 2128.4531 & -10630.1020 & 21170.3750 & -21005.9060 & 10377.7110 & -2040.4490 & 5.0 & $263-313$ & $930-955$ \\
\hline 900 & 1173.7227 & $-\quad 5954.0156$ & 12036.3440 & -12112.8750 & 6062.9375 & -1206.0269 & 2.1 & $258-308$ & $900-925$ \\
\hline 1600 & 405.0256 & -1937.8789 & 3649.2187 & $-\quad 3361.2371$ & 1499.9250 & 254.9616 & 5.3 & $258-308$ & $820-860$ \\
\hline 2000 & 289.0210 & -1330.6213 & 2377.7666 & -2029.9814 & 802.7009 & 108.7889 & 2.2 & $253-303$ & $780-820$ \\
\hline 3000 & 317.4961 & $-\quad 1447.1931$ & 2549.3904 & - 2128.5884 & 808.7541 & 99.7481 & 7.0 & $253-303$ & $680-720$ \\
\hline 4000 & 344.4272 & -1550.0005 & 2679.6853 & $-\quad 2170.1025$ & 777.2478 & 81.1316 & 1.4 & $253-303$ & 595- 635 \\
\hline
\end{tabular}

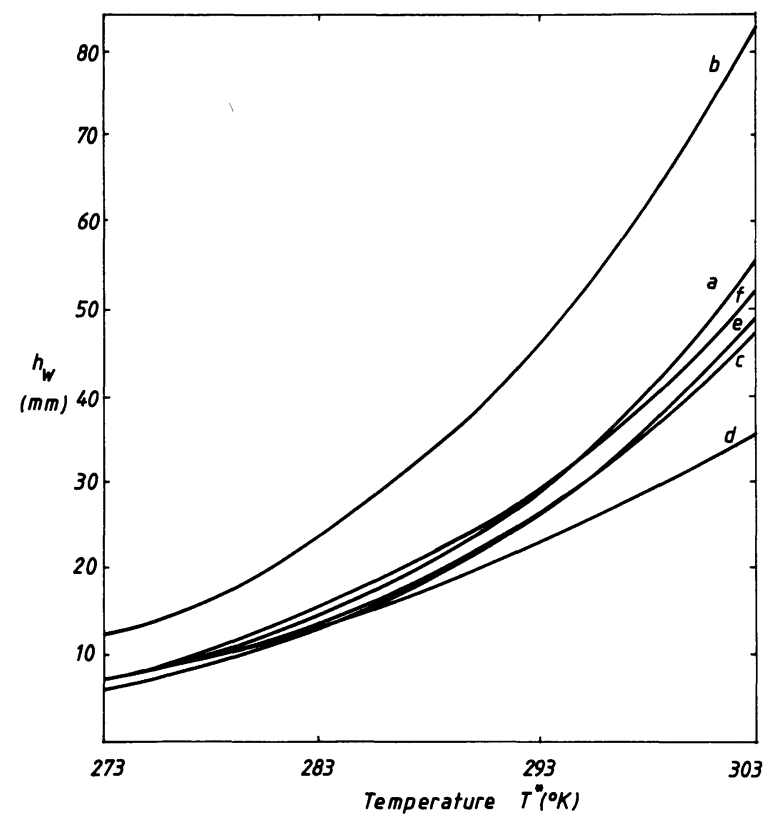

Fig. 2. - The thickness of precipitable water $h_{\mathrm{w}}$ as a function of temperature. a) present work, b) Hann [4], c) Barbaro et al. [11], d) Paltridge and Platt [5], e) Gates [6], f) Smith [7] $\left(h^{*}=0 \mathrm{~m}, p^{*}=1000 \mathrm{hPa}, u^{*}=80 \%\right)$.

difficult to perform altitude measurements of humidity in all the places where we intend to determine solar radiation. Consequently, it appears as more useful to correct the existing formulae which compute precipitable water thickness. One of these corrections is $[13,14]$ :

$$
h_{\mathrm{w}}^{\prime}=h_{\mathrm{w}}\left(\frac{p^{*}}{p_{0}}\right)^{n}\left(\frac{T_{0}}{T^{*}}\right)^{0.5} .
$$

In (12) $h_{\mathrm{w}}^{\prime}$ is the corrected value and $p_{0}, T_{0}$ are scaling values. There isn't an unanimous opinion concerning the value of $n$. According to [13] $n$ varies

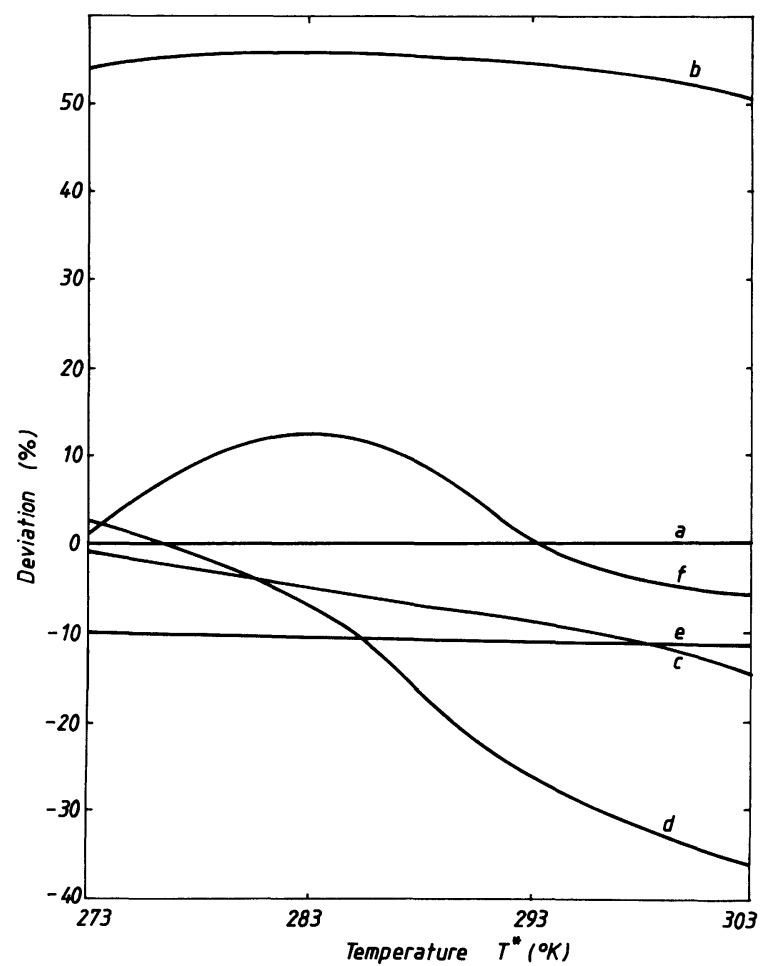

Fig. 3. - Deviations between the curves of figure 2 compared to curve a.

between 0 and 1. In [15] $n$ is equal to 1 and in [16] it is equal to zero. A correction of the type (12) where $n=1$ and the temperature effect is missing has been previously used by Kaplan [17] and Paltridge [18]. In [18] it is shown that this correction slightly reduced the error compared to the case without correction, but the error still remains fairly high. Consequently, equation(12) which takes into consideration the temperature effect, is more useful [14]. It is also mentioned that the corrections of type (12) although improving the results are poorly justified, being semi-empirical [14]. 


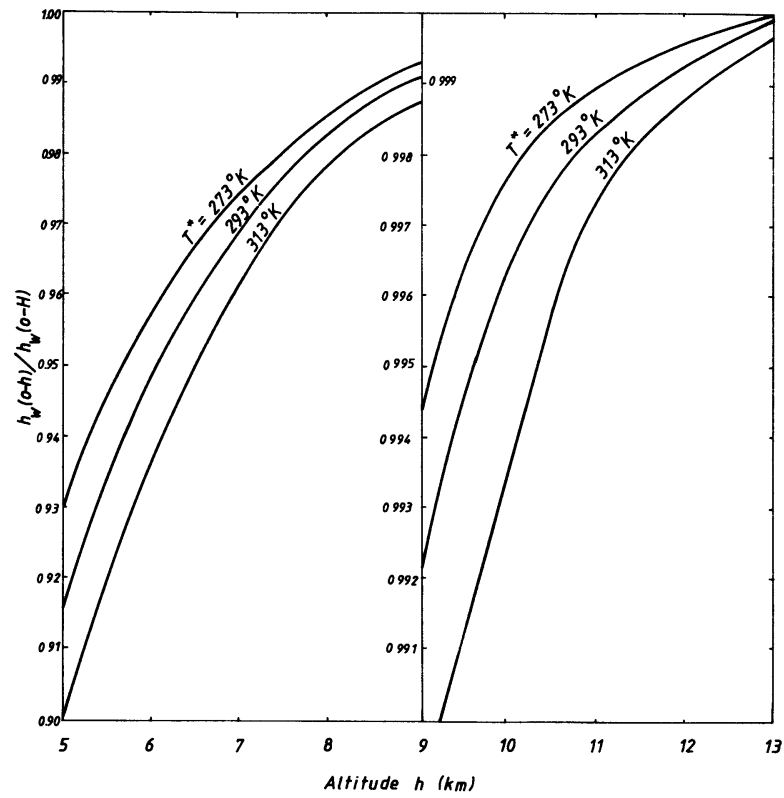

Fig. 4. - The ratio between the thickness of precipitable water from the atmospheric layer $0-h, h_{\mathrm{w}(0-h)}$, and the total precipitable water thickness, $h_{\mathrm{w}(0-H)}\left(h^{*}=0 \mathrm{~m}\right.$, $\left.p^{*}=1000 \mathrm{hPa}, u^{*}=100 \%\right)$.

The atmospheric model we propose allows a theoretical explanation for the large interval of the deviations between the computed and measured values of $h_{\mathrm{w}}$. This fact is owed to the effect introduced by the vertical profile of vapour distribution. The parameter $\alpha$ from (3) can be used to quantify this effect. Figure 5 shows the dependence of $\theta_{\mathrm{w}}$ on $\alpha$ for several temperatures, at constant $p^{*}$ and $u^{*}$. The variation of $\theta_{\mathrm{w}}$ is decreasing and strong. It is approximately linear at lower temperatures and much more abrupt at higher $T^{*}$. The effect of $\alpha$ on $\theta_{\mathrm{w}}$ is of the same importance as that of $T^{*}$. Figure 6 shows the ratio $h_{\mathrm{w}(0-h)} / h_{\mathrm{w}(0-H)}$ for several values of $\alpha$. The variation of $\alpha$ strongly modifies the distribution of precipitable water with altitude. The deviations between the values of $h_{\mathrm{w}}$ computed with various formulae (see Fig. 3 ) are also due to the fact that each of the quoted models is based on different vertical humidity profiles. Our model has the advantage of taking into account various types of humidity distributions by means of $\alpha$. Table III shows the values of the coefficients $c_{j}(j=0,5)$ from (11) for $h^{*}=0 m$ and different $\alpha$.

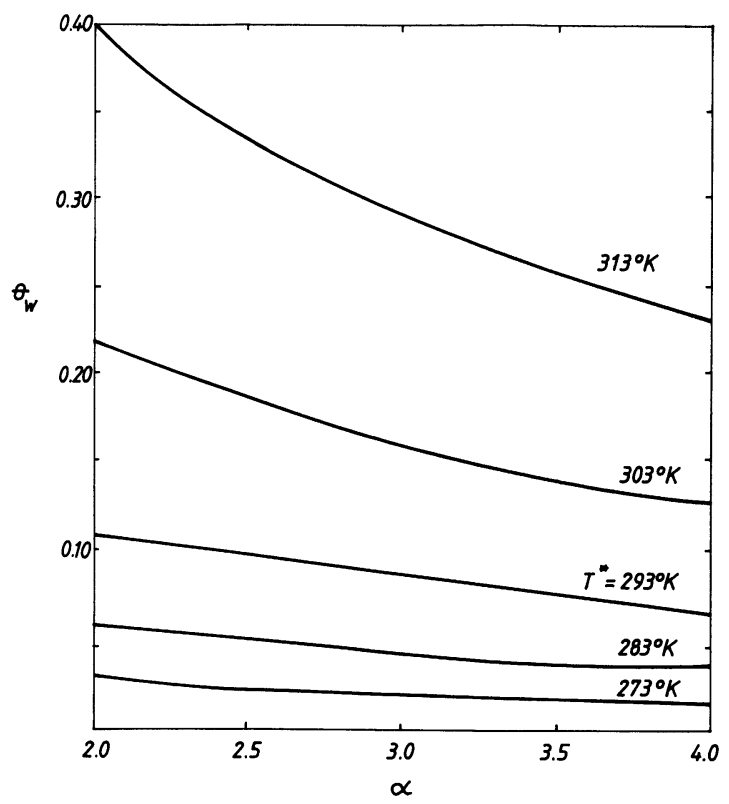

Fig. 5. - The dependence of $\theta_{\mathrm{w}}$ on $\alpha\left(h^{*}=0 \mathrm{~m}\right.$, $\left.p^{*}=1000 \mathrm{hPa}, u^{*}=80 \%\right)$.

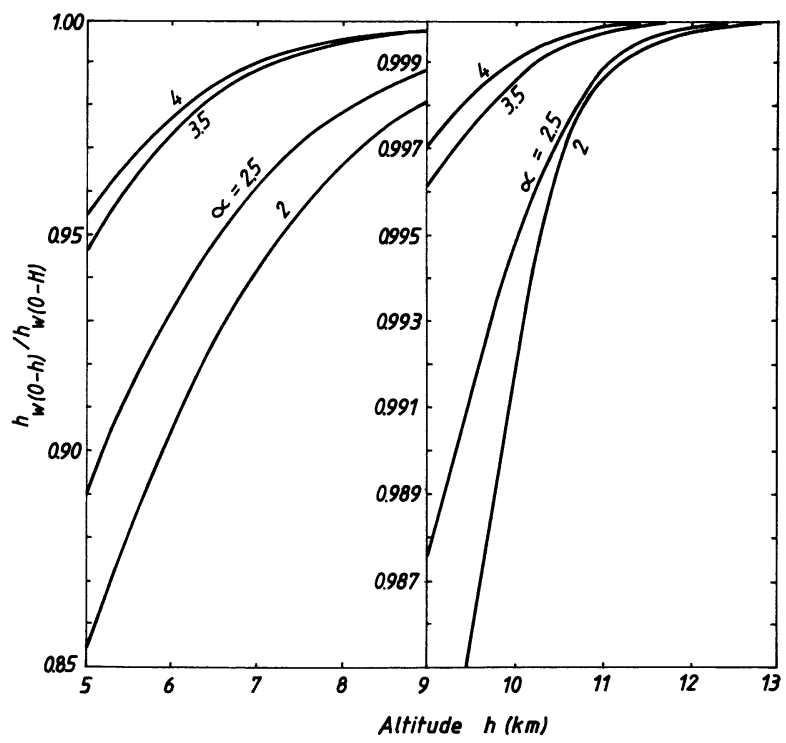

Fig. 6. - The ratio between the thickness of precipitable water from the atmospheric layer $0-h, h_{\mathrm{w}(0-h)}$, and the total precipitable water thickness, $h_{\mathrm{w}(0-H)}$, for some values of $\quad \alpha . \quad\left(h^{*}=0 \mathrm{~m}, \quad p^{*}=1000 \mathrm{hPa}, \quad u^{*}=100 \%\right.$, $\left.T^{*}=293 \mathrm{~K}\right)$.

Table III. - The values of the coefficients $c_{j}$ from equation (11) as a function of $\alpha$ and their interval of validity, for $h^{*}=0 \mathrm{~m}$.

\begin{tabular}{|c|c|c|c|c|c|c|c|c|}
\hline Alfa & $\mathrm{CO}$ & $\mathrm{C} 1$ & $\mathrm{C} 2$ & C3 & $\mathrm{C} 4$ & C5 & $\begin{array}{l}\text { Temp. } \\
\text { (K) }\end{array}$ & $\begin{array}{l}\text { Pres. } \\
(\mathrm{hPa})\end{array}$ \\
\hline 2 & 2610.6758 & -13038.4800 & 25966.375 & -25763.699 & 12727.4300 & -2502.1960 & $263-313$ & $1000-1025$ \\
\hline 2.5 & 2181.5742 & -10895.5740 & 21698.406 & -21527.906 & 10633.8120 & -2090.2290 & $263-313$ & $1000-1025$ \\
\hline 3.5 & 1649.6641 & $-\quad 8239.2187$ & 16408.203 & -16278.473 & 8039.9766 & -1580.0820 & $263-313$ & $1000-1025$ \\
\hline 4 & 1471.3633 & -7348.7305 & 14634.750 & -14518.766 & 7170.5781 & -1409.1296 & $263-313$ & $1000-1025$ \\
\hline
\end{tabular}




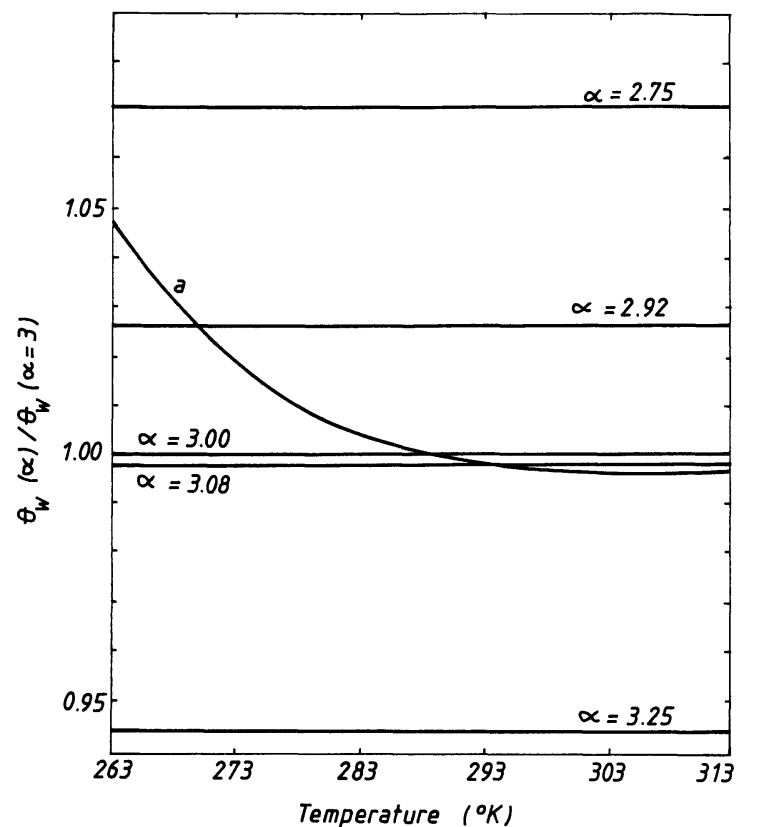

Fig. 7. - The dependence on temperature of $(288.16 / T)^{0.5} \quad$ (curve a) and respectively $\theta_{\mathrm{w}}(\alpha) / \theta_{\mathrm{w}}(\alpha=3) . \quad\left(h^{*}=0 \mathrm{~m}, \quad p^{*}=1015 \mathrm{hPa}\right.$, $\left.u^{*}=100 \%\right)$.

In figure 7 we present the function $\left(T_{0} / T\right)^{0.5}$ used in (12) to introduce the temperature correction. We have chosen $T_{0}=288.16 \mathrm{~K}$, according to the TSA60 and CIRA-61 models. We also present in figure 7 the function $\theta_{\mathrm{w}}(\alpha) / \theta_{\mathrm{w}}(\alpha=3)$, for several values of $T^{*}=T$. The correction of the type $\left(T_{0} / T\right)^{0.5}$ can properly model only a small part of the vertical distributions of humidity (values of $\alpha$ between 2.9 and 3.1). Taking into account (8a) and what we mentioned above, we propose a relation to calculate the corrected thickness of precipitable water :

$$
\tilde{h}_{\mathrm{w}}=h_{\mathrm{w}}^{*} \frac{\tilde{p}}{p^{*}} \frac{\theta_{\mathrm{w}}(\tilde{p}, \tilde{T}, \tilde{u}, \alpha)}{\theta_{\mathrm{w}}\left(p^{*}, T^{*}, u^{*}, \alpha=3\right)} \frac{\rho_{\mathrm{w}}\left(T^{*}\right)}{\rho_{\mathrm{w}}(\tilde{T})} .
$$

In (13) $h_{\mathrm{w}}^{*}$ and $\tilde{h}_{\mathrm{w}}$ correspond to the atmospheric states $\left(^{*}\right)$ and $(\sim)$, characterised by $\left(h^{*}\right.$, $\left.p^{*}, T^{*}, w^{*}, \alpha=3\right)$ and $(\tilde{h}, \tilde{p}, \tilde{T}, \tilde{w}, \alpha)$, respectively. Establishing the values of $\alpha$ from (13) for a real atmospheric situation is a difficult task. However, the distribution of water vapour significantly depends on the atmospheric thermal stratification, upon which a first information is provided by $T^{*}$ and $a_{1}$. High values of $T^{*}$ and low values of $\left|a_{1}\right|$ (stable atmosphere) correspond to a stronger thermal stratification, which prevents vapour convection in altitude. This fact is equivalent to high values of $\alpha$. Similarly, low values of $T^{*}$ and high values of $\left|a_{1}\right|$ can be related to small values of $\alpha$. Intermediate values of $T^{*}$ and $a_{1}$ are also possible. We agree to ascribe the average value of $\alpha$ to the average, neutral atmosphere defined by the TSA- 60 model. Consequently, the value $\alpha=3$ corresponds in average, to a temperature $T^{*}=288.16 \mathrm{~K}$ and $a_{1}=$ $-0.0065 \mathrm{~K} / \mathrm{m}$. Our previous analysis makes possible to distinguish three particular cases for which we can suggest average values of $\alpha$ : (a) unstable atmosphere and $\tilde{T}=263-283 \mathrm{~K}$ with $\alpha=2.75$, (b) neutral atmosphere and $\tilde{T}=283-293 \mathrm{~K}$, with $\alpha=3$ and (c) stable atmosphere and $\tilde{T}=293-313 \mathrm{~K}$, with $\alpha=3.25$. Nevertheless, it should be mentioned that $\alpha$ also depends on other meteorological parameters, such as wind speed.

Equation (13) allows a short discussion on the values of the coefficient $n$ from (12). In case that between the states $\left({ }^{*}\right)$ and $(\sim)$ there is a transformation at constant $w$, the function $\theta_{\mathrm{w}}$ does not depend on pressure, as we showed in Appendix B. Consequently, the correction (13) is linear in $\tilde{p}$, which correspond to $n=1$ in (12). Transformation at constant $w$ can occur if the states $\left({ }^{*}\right)$ and $(\sim)$ characterize the same geographical place, during a rather short time interval. If the transformation $(*) \rightarrow(\sim)$ has not constant $w, \theta_{\mathrm{w}}$ depends on pressure in the form (11). In this case the correction

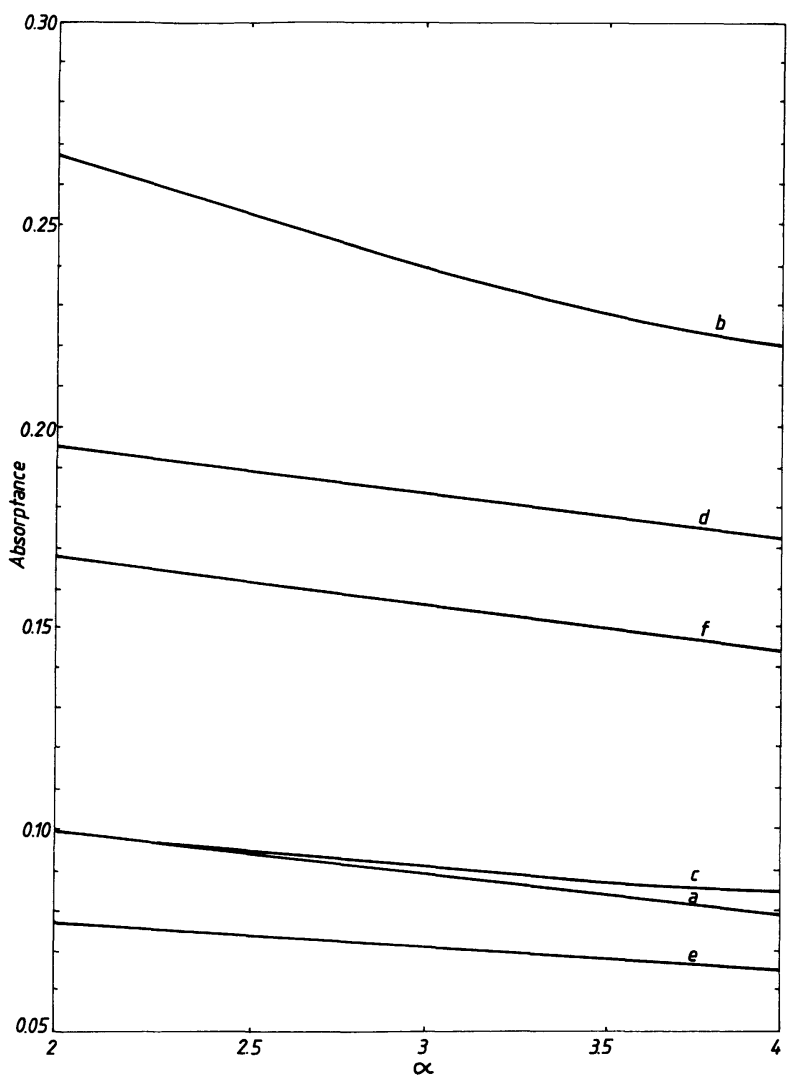

Fig. 8. - The dependence on $\alpha$ of water vapour absorbtance of solar radiation $\left(h^{*}=0 \mathrm{~m}, p^{*}=1000 \mathrm{hPa}\right.$, $u^{*}=80 \%$ ). a, b) Yamamoto [11], c, d) Lacis and Hansen [13], e, f) McDonald [20]. The two letters correspond to $T^{*}=273 \mathrm{~K}$ and $313 \mathrm{~K}$, respectively. 
(13) will be approximatively proportional to $(\tilde{p})^{0.05}$. Such situations generally appear when correction is applied in different geographical places.

Figure 8 shows the dependence on $\alpha$ of solar radiation absorption by water vapour. The formulae proposed by Yamamoto [11] Lacis and Hansen [13] and McDonald [20] were used. The differences between these three formulae are important, especially in case of high temperatures, as they can reach $10 \%$. The differences decrease with high $\alpha$ values. In case of the Yamamoto relation, considered as the most precise [18], the range of variation of solar radiation absorption is approximatively $5 \%$. Consequently, our model allows a partial explanation of the deviations observed between the calculated and measured values, which can reach $20 \%$ [18]. In our opinion this phenomenon is due to the fact that the vertical humidity profile has not been taken into account in a proper manner.

\section{Testing of atmospheric model.}

It is important to know how much the functions $\theta_{\mathrm{w}}$ and $\theta_{g i}$ depend upon the details of the atmospheric model we used.

An important parameter of the model is the coefficient $a_{1}$. This coefficient is strongly related to the statical atmospheric stability [21, 22]. The standard value we used corresponds to a neutral atmosphere. The atmosphere is stable or not stable if the module of the thermal gradient in troposphere is lower, respectively higher, than the standard value of $\left|a_{1}\right|$. We have performed single precision calculation for $a_{1}$ varying between -0.0040 and $-0.0090 \mathrm{~K} / \mathrm{m}$. For a temperature $T^{*}$ in the range of 273 and $293 \mathrm{~K}$ the function $\theta_{\mathrm{w}}$ does not depend on the thermal gradient $a_{1}$. At $T^{*}=313 \mathrm{~K}$ a very weak dependence appears, which results in a $\theta_{\mathrm{w}}$ deviation of $0.006 \%$ for the whole variation of $a_{1}$.

Another important parameter of the atmospheric model is the troposphere depth $h_{1}$. Measurements have proved that this parameter varies according to the latitude and the season $[8,23]$. Figure 9 shows the dependence of $\theta_{\mathrm{w}}$ on troposphere depth, for several temperatures at constant $p^{*}$ and $u^{*}$. This dependence is weak, being more stressed for lower values of $h_{1}$. At heights above $15 \mathrm{~km}$ the function $\theta_{\mathrm{w}}$ tends to a constant value. The dependence is strongly influenced by temperature, especially for weak troposphere depths. Also for lower heights, $h_{1}$ substantially increases the dispersion that temperature induced on $\theta_{\mathrm{w}}$ values. Consequently, it is much more useful to take into account the temperature dependence of the precipitable water thickness during the warm season and within the regions placed at higher latitudes (more than $30^{\circ} \mathrm{N}$ and S).

Measurements performed with rockets show an important variation during the year of the REVUE DE PHYSIQUE APPLIQUÉE. - T. 23, N 12, DÉCEMBRE 1988

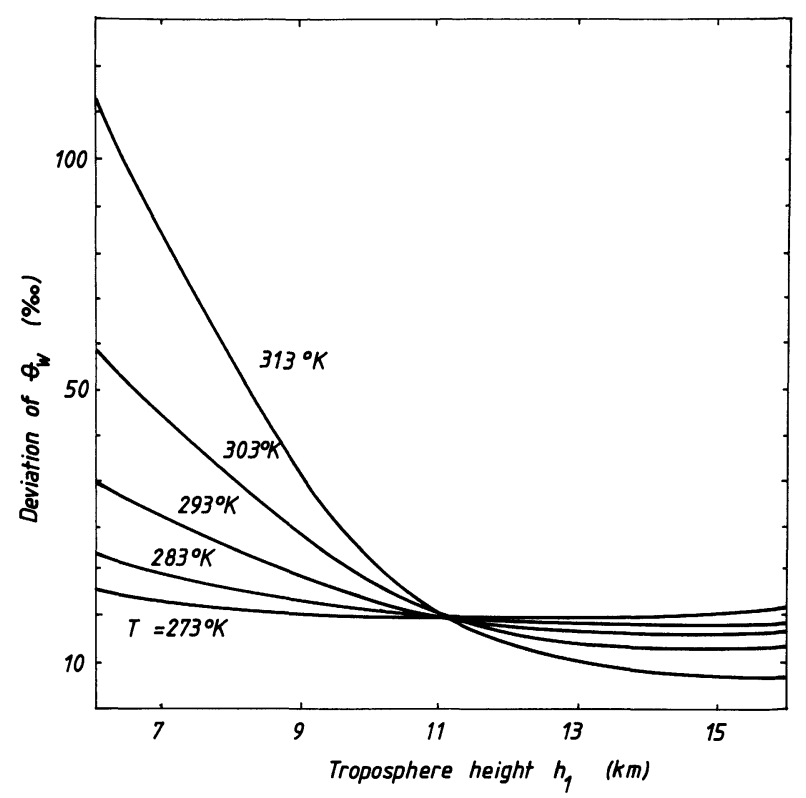

Fig. 9. - The deviation of $\theta_{\mathrm{w}}$ compared to the value from the standard model $\left(h_{1}=11 \mathrm{~km}\right)$ for some values of the stratosphere height $h_{1} . \quad\left(h^{*}=0 \mathrm{~m}, p^{*}=1000 \mathrm{hPa}\right.$, $\left.u^{*}=80 \%\right)$.

tropopause height $h_{2}$ and the thermal gradient from the stratosphere $a_{3}$ [23]. We have performed calculations in single precision for $h_{2}$ values in the range of 21 and $29 \mathrm{~km}$ and for $a_{3}$ between 0.0005 and $0.0050 \mathrm{~K} / \mathrm{m}$. Our results show a complete independence of $\theta_{\mathrm{w}}$ on these parameters.

Figures 10 and 11 show the influence of the thermal gradient of the troposphere and the troposphere height upon the values of $\theta_{g i} \cdot \theta_{g i}$ slightly increases with $a_{1}$. It becomes stronger when temperature increases. The troposphere height slightly influences $\theta_{g i}$ values, but more strongly compared to the thermal gradient $a_{1}$. Even this influence is intensified in case of higher temperatures.

The thermal gradient from the stratosphere and the tropopause height influence the function $\theta_{g i}$ in the manner showed in figures 12 and 13. $\theta_{g i}$ slightly depends both on the thermal gradient $a_{3}$ and the height $h_{2}$, decreasing in the first case and increasing in the second one. In both situations the dependence is less influenced by temperature. The tropopause and stratosphere influences are much more reduced than those of troposphere.

The parameter $\alpha$ slightly influences $\theta_{g i}$ compared to $\theta_{w}$ (Fig. 14). Increasing temperature intensifies the dependence of $\theta_{g i}$ on $\alpha$. In case of higher temperatures this dependence becomes nonlinear.

Our results have been obtained by means of an atmospheric model whose frame is constituted by the TSA- 60 model. But this model takes into account both seasonal and latitudinal average variations. That is why a comparison with the results obtained through other atmosphere models is useful. Table IV 


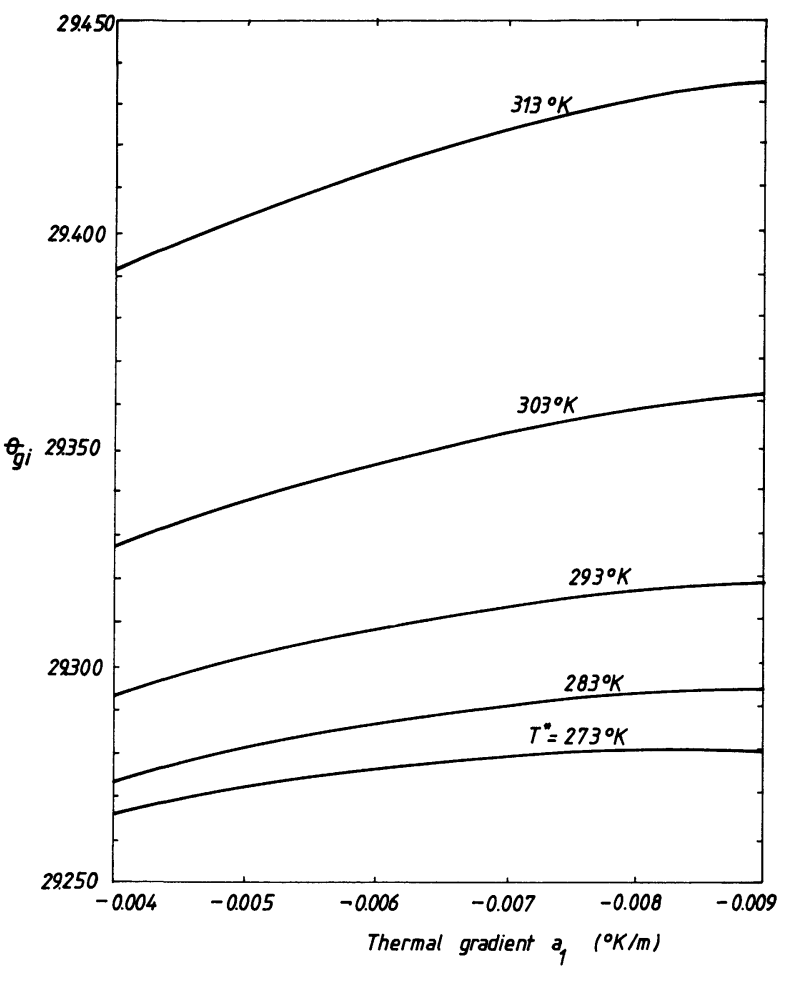

Fig. 10. - The dependence of $\theta_{g i}$ on the thermal gradient $a_{1}\left(h^{*}=0 \mathrm{~m}, p^{*}=1000 \mathrm{hPa}, u^{*}=80 \%\right)$.

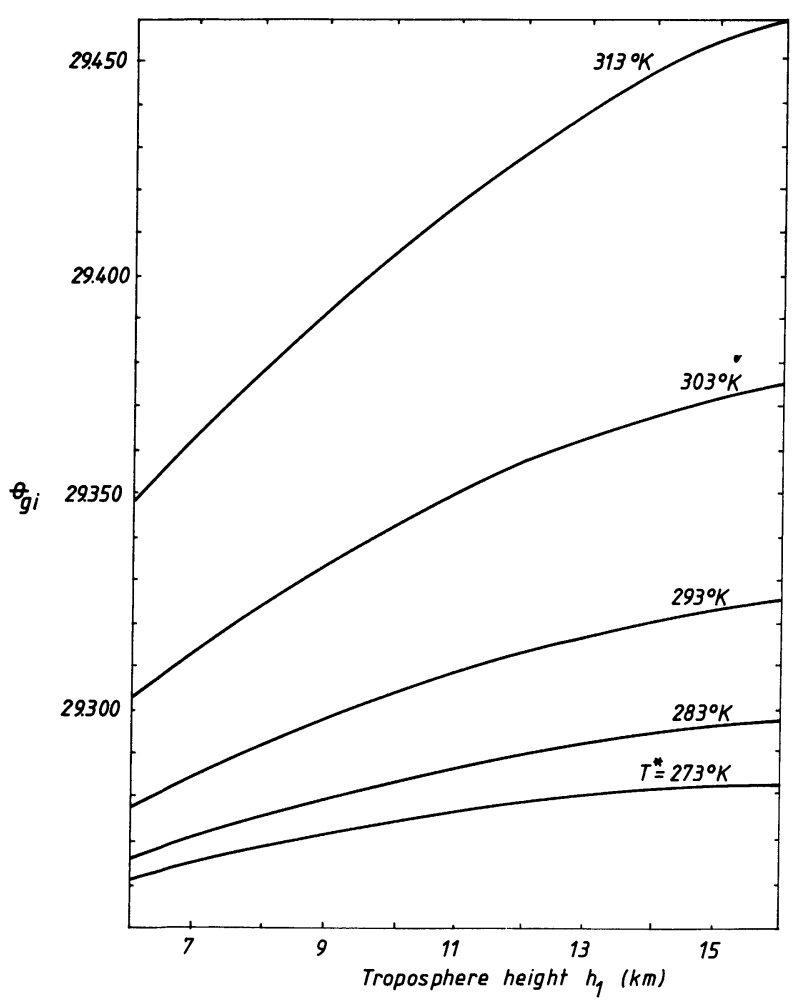

Fig. 11. - The dependence of $\theta_{g i}$ on the troposphere height $h_{1}(\mathrm{~m}),\left(h^{*}=0 \mathrm{~m}, p^{*}=1000 \mathrm{hPa}, u^{*}=80 \%\right)$.

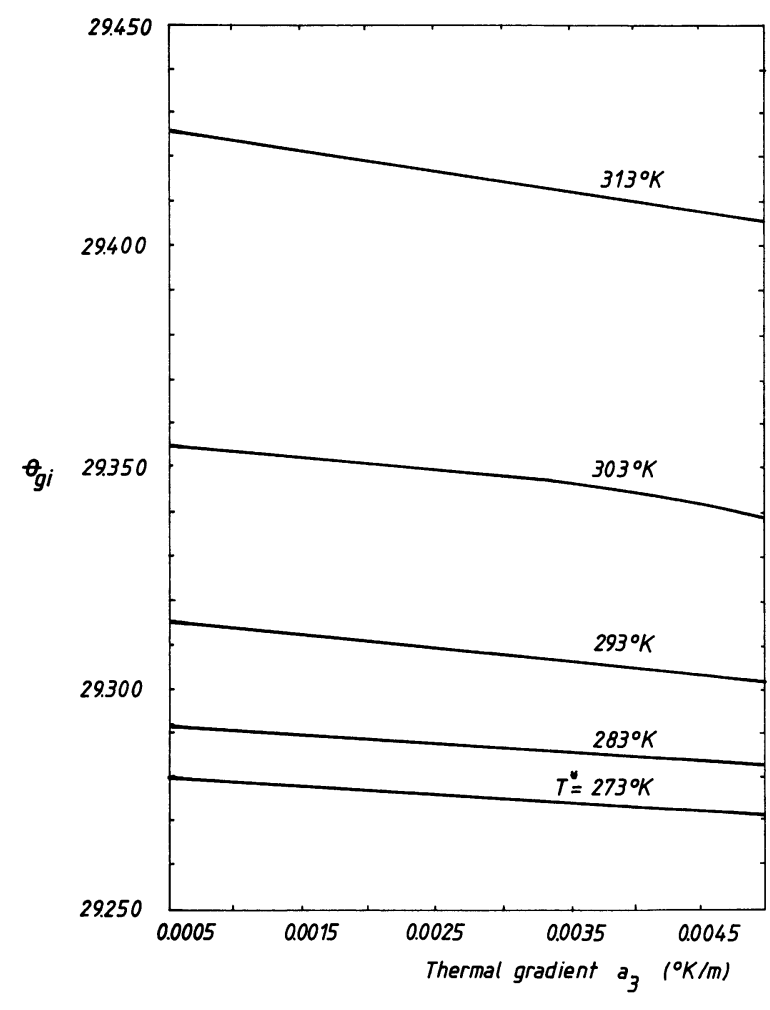

Fig. 12. - The dependence of $\theta_{g i}$ on the thermal gradient $a_{3}\left(h^{*}=0 \mathrm{~m}, p^{*}=1000 \mathrm{hPa}, u^{*}=80 \%\right)$.

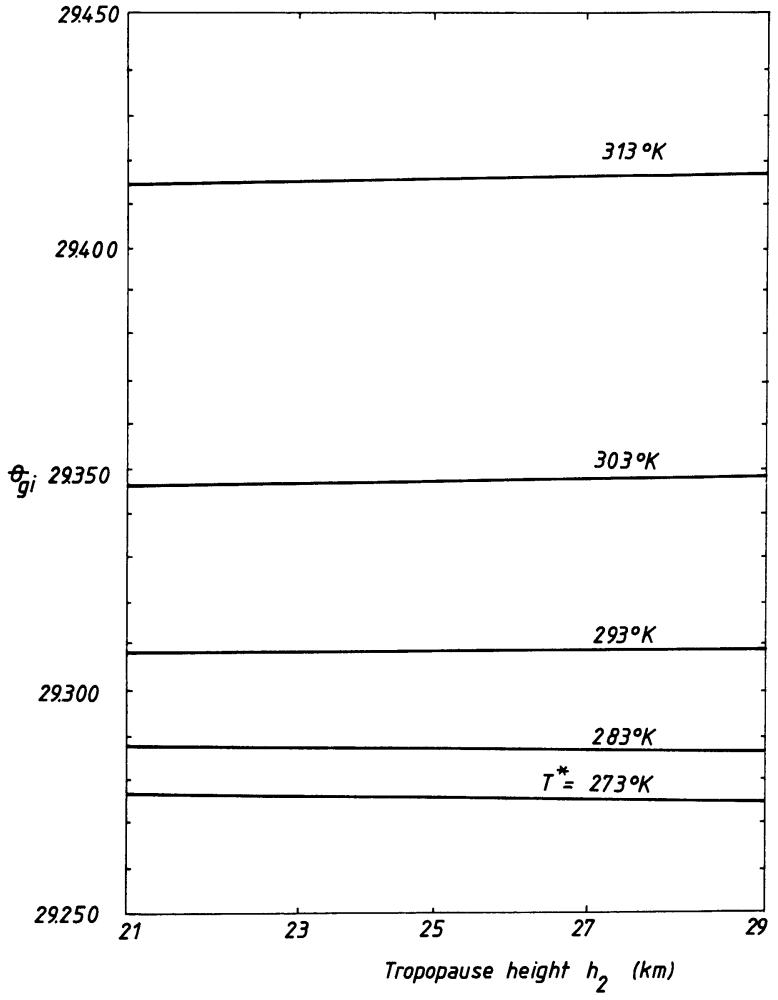

Fig. 13. - The dependence of $\theta_{g i}$ on the tropopause height $h_{2}\left(h^{*}=0 \mathrm{~m}, p^{*}=1000 \mathrm{hPa}, u^{*}=80 \%\right)$. 


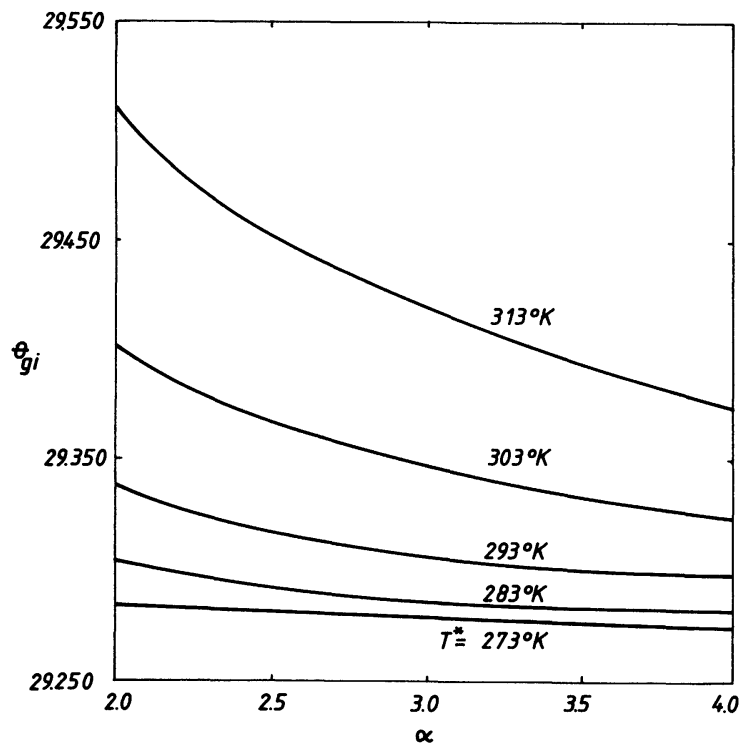

Fig. 14. - The dependence of $\theta_{g i}$ on $\alpha\left(h^{*}=0 \mathrm{~m}\right.$, $p^{*}=1000 \mathrm{hPa}, u^{*}=80 \%$ ).

Table IV. - The constants $h_{1}, h_{2}, h_{3}, h_{4}$ and $a_{1}, a_{3}$ for six atmospheric models.

\begin{tabular}{|c|c|c|c|c|c|c|}
\hline Model & $h_{1}$ & & $\begin{array}{l}h_{3} \\
\mathrm{n})\end{array}$ & $h_{4}$ & $a_{1}$ & 1) \\
\hline a & 16 & 16 & 50 & 50 & -0.0065 & 0.0023 \\
\hline b & 11 & 31 & 50 & 50 & -0.0050 & 0.0021 \\
\hline c & 9 & 36 & 50 & 50 & -0.0044 & 0.0021 \\
\hline d & 16 & 16 & 50 & 50 & -0.0060 & 0.0023 \\
\hline e & 16 & 16 & 50 & 50 & -0.0050 & 0.0017 \\
\hline f & 9 & 31 & 50 & 50 & -0.0061 & 0.0015 \\
\hline
\end{tabular}

shows the physical characteristics of six atmospheric models, obtained from measurements with rockets [23]. The numerical values are obtained after slightly linearising the curves from the paper. Each of the six models characterizes a given latitudinal band and a certain period of the year. So, the models a, b, c, are specific to the January-February months : (a) in the tropical regions (maritime and continental) : $15^{\circ} \mathrm{S}-$ $15^{\circ} \mathrm{N}$; (b) in the continental regions between $30^{\circ} \mathrm{N}-45^{\circ} \mathrm{N}$; (c) in the continental areas between $60^{\circ} \mathrm{N}-90^{\circ} \mathrm{N}$. The models $\mathrm{d}$, e, f characterize the July-August months for the same geographical areas. In all cases we considered a neutral atmosphere. Figure 15 shows the values $\theta_{\mathrm{w}}$ predicted by our model and by the six atmospheric models, respectively. The dependence of results upon the model is small. This dependence increases at high temperatures. The dependence on latitude is stronger than the dependence on the period of the year. The atmospheres in the regions placed at a

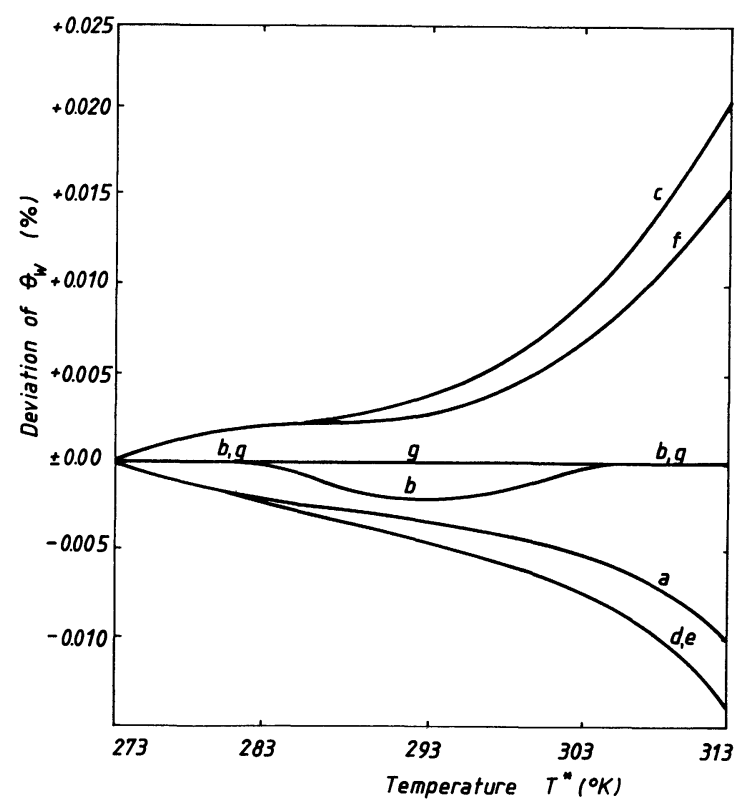

Fig. 15. - The deviation of $\theta_{\mathrm{w}}$ for six atmospheric models compared to the value of $\theta_{\mathrm{w}}$ from the standard model $\left(h^{*}=0 \mathrm{~m}, p^{*}=1000 \mathrm{hPa}, u^{*}=80 \%\right)$. a, b, c, d, e, f) the atmospheric models, g) standard model.

latitude higher than $60^{\circ}$ determine positive deviations compared to the standard model, while those in the tropical regions lead to negative deviations. In the last case the deviations have a lower absolute value.

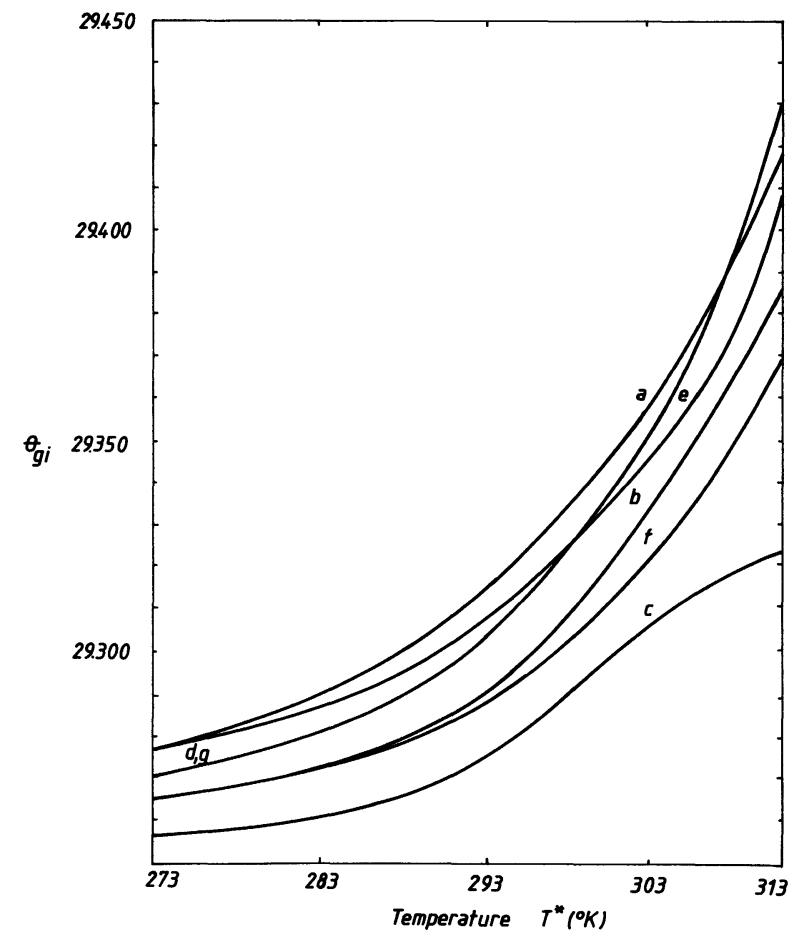

Fig. 16. - The dependence of $\theta_{g i}$ on temperature for six atmospheric models (curves a, b, c, d, e, f) and the standard model (curve g) $\left(h^{*}=0 \mathrm{~m}, p^{*}=1000 \mathrm{hPa}\right.$, $\left.u^{*}=80 \%\right)$. 
It can be noticed that the model $b$ gives the closest results to the standard model. Hence, the model we propose has the best precision during the cold season.

Figure 16 shows the values $\theta_{g i}$ corresponding to the six models of atmosphere and to the standard model, respectively. The dependence of $\theta_{g i}$ on model is rather reduced. For all models the temperature influence has the same size. The latitude influence is more important especially during cold season (see the curves $a, b, c)$. The influence of the period from the year is less important, as it can be noticed by comparing the curves a and $c$. Both the dependence on latitude and on the period of the year are amplified with an increasing temperature. At lower temperatures the standard model is characterized by values close to the average of the other models. On the contrary, in case of higher temperatures, the results of the standard model are larger than for other models.

\section{Conclusions.}

Applying equations (8) one may compute the thickness of precipitable water and of an equivalent homogeneous layer from any gas which is a permanent atmospheric component. Deduction of these equations is wholly theoretically justified. Compared to other models our approach has two advantages. Firstly, it takes into account the humidity of the upper troposphere (above $5 \mathrm{~km}$ altitude), which stands for 5 to $10 \%$ from the total atmospheric precipitable water. Secondly, our model allows to take into account various altitudinal distributions of the humidity content, which may be connected with the stable, neutral or unstable state of the atmosphere.

The parameters with a larger effect on the quantity of precipitable water are air temperature and the vertical profile of humidity content. The variation of water vapour vertical distribution requires correction of the expression of precipitable water thickness. The formula we propose is theoretically justified and allows us to make a brief discussion concerning the limits of validity and the accuracy of certain empirical relations.

Since results are little dependent on the details of our atmospheric model they may be used with good approximation during the whole year and on the whole surface of the Earth. The theory was compared with the results obtained from six atmospheric models based on measurements. It was found out a good concordance.

\section{Acknowledgements.}

The author thanks the referee for her suggestions and remarks.

\section{Appendix A.}

A simple atmospheric model was developed to compute the total mass of water vapour, $m_{\mathrm{w}}$, and of gas $i, m_{i}$, which exist in an atmospheric column. We section the atmospheric column with two planes perpendicular on Nadir-Zenith direction, placed at the distance $h$ and respectively $h+\mathrm{d} h$ above sea level. The two planes delimit a cylinder of $\mathrm{d} h$ height and $\mathrm{d} V$ volume. Within the volume $\mathrm{d} V$ there is a mixture of gases, water vapour and aerosols. The volume of the liquid and solid phases can be neglected compared to the gaseous phase volume. Consequently, we have :

$$
\mathrm{d} V=\mathrm{d} V_{\mathrm{a}}+\mathrm{d} V_{\mathrm{w}}
$$

where $\mathrm{d} V_{\mathrm{a}}$ and $\mathrm{d} V_{\mathrm{w}}$ represent the volume occupied by permanent gases (shortly: gases) and water vapour, respectively. We index with $i$ the gases composing the dry air. Then, the partial volume $\mathrm{d} V_{i}$ of gas $i$ represent a fraction $\kappa_{i}$ from the volume $\mathrm{d} V_{\mathrm{a}}$ of dry air :

$$
\mathrm{d} V_{i}=\kappa_{i} \mathrm{~d} V_{\mathrm{a}} .
$$

Up to about $400 \mathrm{~km}$ altitude the gaseous mixture from the volume $\mathrm{d} V$ is in thermodynamical equilibrium [8], characterized by the pressure $p$ and the temperature $T$. Moreover, we considered that both each gas separately and water vapour are perfect gases.

We define the water vapour content $w$ as the ratio between the weights of water vapour and dry air from the volume $\mathrm{d} V$ (see e.g. [25]). We note with $\mathrm{d} n_{i}, \mathrm{~d} n_{\mathrm{w}}$ the particle number of $i$ type and respectively water vapour from the volume $\mathrm{d} V$ and by $M_{i}, M_{\mathrm{w}}$ the mass of one particle from the respective species. Then, the humidity content is given by :

$$
w=\frac{g M_{\mathrm{w}} \mathrm{d} n_{\mathrm{w}}}{g \sum_{i} M_{i} \mathrm{~d} n_{i}} .
$$

In (A.3) $g$ designates the gravitational acceleration of the Earth at altitude $h$.

The gaseous phase from $\mathrm{d} V$ (gases and water vapour) constitutes a thermodynamic system completely defined by the macroscopic parameters $p, T, w, \kappa_{i}$. At the same time, the aerosols from $\mathrm{d} V$ constitute another thermodynamic system, which is not characterized by the parameters $p$ and $T$ [8]. However, our results are independent of aerosols existence, if these constituents do not destroy the thermodynamical equilibrium of the gaseous phase, by starting certain kinetic processes such as water vapour condensation.

In the partial volumes $\mathrm{d} V_{i}$ and $\mathrm{d} V_{\mathrm{w}}$ we have :

$$
\begin{gathered}
p \mathrm{~d} V_{i}=M_{i} \mathrm{~d} n_{i} R_{i} T \\
p \mathrm{~d} V_{\mathrm{w}}=M_{\mathrm{w}} \mathrm{d} n_{\mathrm{w}} R_{\mathrm{w}} T
\end{gathered}
$$


where $R_{i}, R_{\mathrm{w}}$ are the constant of perfect gases per unit mass of gas $i$ and water vapour, respectively. Using $\mathrm{d} n_{i}, \mathrm{~d} n_{\mathrm{w}}$ from (A.4) and (A.3) it results :

$$
w=\frac{\mathrm{d} V_{\mathrm{w}}}{\mathrm{d} V_{\mathrm{a}}}\left(R_{\mathrm{w}} \sum_{i} \frac{\kappa_{i}}{R_{i}}\right)^{-1} .
$$

We note $R_{\mathrm{a}}$ the constant of perfect gases per unit mass of dry air. A simple calculation shows :

$$
\sum_{i} \frac{\kappa_{i}}{R_{i}}=\frac{1}{R_{\mathrm{a}}}
$$

Noting $A=R_{\mathrm{w}} / R_{\mathrm{a}}$ and taking into account (A.6), the equation (A.5) becomes :

$$
\mathrm{d} V_{\mathrm{w}}=A w \mathrm{~d} V_{\mathrm{a}} .
$$

By using (A.1), (A.7) and taking into consideration that $\sum_{i} \kappa_{i}=1$, we obtain :

$$
\begin{aligned}
\mathrm{d} V_{i} & =\frac{\kappa_{i}}{1+A w} \mathrm{~d} V \\
\mathrm{~d} V_{\mathrm{w}} & =\frac{A w}{1+A w} \mathrm{~d} V .
\end{aligned}
$$

By means of equations (A.4) and (A.8) it can be found out the number of molecules contained in the volume $\mathrm{d} V=S \mathrm{~d} h$ :

$$
\begin{aligned}
\mathrm{d} n_{i} & =\frac{S}{R_{i} M_{i}} \frac{\kappa_{i}}{1+A w} \frac{p}{T} \mathrm{~d} h \\
\mathrm{~d} n_{\mathrm{w}} & =\frac{S}{R_{\mathrm{w}} M_{\mathrm{w}}} \frac{A w}{1+A w} \frac{p}{T} \mathrm{~d} h .
\end{aligned}
$$

To compute the total mass of water vapour, $m_{\mathrm{w}}$, and of gas $i, m_{i}$, we integrate the equation (A.9) :

$m_{\mathrm{w}}=M_{\mathrm{w}} \int_{h^{*}}^{H} \mathrm{~d} n_{\mathrm{w}}=\frac{S}{R_{\mathrm{w}}} \int_{h^{*}}^{H} \frac{A w(h)}{1+A w(h)} \frac{p(h)}{T(h)} \mathrm{d} h$

$m_{i}=M_{i} \int_{h^{*}}^{H} \mathrm{~d} n_{i}=\frac{S}{R_{i}} \int_{h^{*}}^{H} \frac{\kappa_{i}(h)}{1+A w(h)} \frac{p(h)}{T(h)} \mathrm{d} h$.

\section{Appendix B.}

The pressure difference between the two planes defining the volume $\mathrm{d} V$ is :

$$
\mathrm{d} \rho=-\rho(h) g \mathrm{~d} h
$$

where $\rho(h)$ is the density of the gaseous phase at altitude $h$. This density is given by :

$$
\rho=\sum_{i} \rho_{i}+\rho_{\mathrm{w}} .
$$

The definition of $\rho_{i}$ and $\rho_{\mathrm{w}}$ are :

$$
\begin{gathered}
\rho_{i}=M_{i} \mathrm{~d} n_{i} / \mathrm{d} V \\
\rho_{\mathrm{w}}=M_{\mathrm{w}} \mathrm{d} n_{\mathrm{w}} / \mathrm{d} V .
\end{gathered}
$$

By using equations (A.4) and (A.8) it results :

$$
\begin{gathered}
\rho_{i}=\frac{1}{R_{i}} \frac{\kappa_{i}}{1+A w} \frac{p}{T} \\
\rho_{\mathrm{w}}=\frac{1}{R_{\mathrm{w}}} \frac{A w}{1+A w} \frac{p}{T} .
\end{gathered}
$$

Taking into account (B.4) the equation (B.2) becomes :

$$
\rho=\frac{1}{R_{\mathrm{a}}} \frac{1+w}{1+A w} \frac{p}{T}
$$

Replacing (B.5) into (B.1) we obtain the equation which gives the pressure distribution on the atmosphere height :

$$
\frac{\mathrm{d} p}{p}=-\frac{g}{R_{\mathrm{a}}} \frac{1+w}{1+A w} \frac{\mathrm{d} h}{T} .
$$

To solve equation (B.6) we note :

$$
\pi(h)=\frac{p(h)}{p^{*}} .
$$

Replacing (3) in (B.6) we obtain :

$$
\frac{1+A w^{*} \pi^{\alpha}}{1+w^{*} \pi^{\alpha}} \frac{\mathrm{d} \pi}{\pi}=-\frac{g}{R_{\mathrm{a}}} \frac{\mathrm{d} h}{T} .
$$

To solve equation (B.8) we integrate the left member between $h^{*}$ and $h$, obtaining [24] :

$\ln \left[\pi\left(\frac{1+w^{*} \pi^{\alpha}}{1+w^{*}}\right)^{\frac{A-1}{\alpha}}\right]=-\int_{h^{*}}^{h} \frac{g}{R_{\mathrm{a}}} \frac{\mathrm{d} h}{T}$.

We note :

$$
\begin{gathered}
\beta=\frac{A-1}{\alpha} \\
D=\ln \left(1+w^{*}\right)^{\beta} .
\end{gathered}
$$

From (B.9) we obtain :

$$
\ln \left[\pi\left(1+w^{*} \pi^{\alpha}\right)^{\beta}\right]=D-\int_{h^{*}}^{h} \frac{g}{R_{\mathrm{a}}} \frac{\mathrm{d} h}{T} .
$$

In the common cases the maximum value of $w^{*}$ does not exceed 0.04 . Consequently, considering $w^{*} \pi^{\alpha}$ as a small parameter we have :

$$
\left(1+w^{*} \pi^{\alpha}\right)^{\beta} \cong 1+\beta w^{*} \pi^{\alpha} .
$$

Taking into account (B.13), from (B.12) we obtain :

$$
\ln \left(\pi+\beta w^{*} \pi^{\alpha+1}\right)=D-\int_{h^{*}}^{h} \frac{g}{R_{\mathrm{a}}} \frac{\mathrm{d} h}{T} .
$$


We note :

$$
F=\exp \left(D-\int_{h^{*}}^{h} \frac{g}{R_{\mathrm{a}}} \frac{\mathrm{d} h}{T}\right) .
$$

Equation (B.14) has then the form :

$$
\pi+\beta w^{*} \pi^{\alpha+1}=F .
$$

We consider the non-disturbed equation :

$$
\pi_{0}=F
$$

and we are looking for a solution of equation (B.16) with the form:

$$
\pi=\pi_{0}+\pi_{1} .
$$

Replacing (B.18) in (B.16) and taking into account (B.17) we obtain :

$$
\pi_{1}+\beta w^{*}\left(F+\pi_{1}\right)^{\alpha+1}=0 .
$$

We develop with Newton's relation the binominal of $\alpha+1$ order from (B.19) and we renounce to the terms containing $\pi_{1}$ at powers greater or equal to 2 . Finally, we obtain :

$$
\pi_{1}=-\frac{\beta w^{*} F^{\alpha+1}}{1+(\alpha+1) \beta w^{*} F^{\alpha}} .
$$

Replacing (B.20) in (B.18) we obtain :

$$
\pi=F\left(1-\frac{\beta w^{*} F^{\alpha}}{1+(\alpha+1) \beta w^{*} F^{\alpha}}\right) .
$$

\section{Appendix C.}

We will determine the pressure $p$ and the humidity content $w$ at altitude $h$ over sea level. The calculation is performed by differentiation, according to the thermal strata $k(k=1,4)$, assuming as known the values $T_{k}^{0}, p_{k}^{0}, w_{k}^{0}$ at the stratum base. Remark that $T_{1}^{0}=T^{*}, p_{1}^{0}=p^{*}, w_{1}^{0}=w^{*}$. Firstly, we observe that up to $90 \mathrm{~km}$ altitude the dry air composition does not modify [8]. This fact implies the constancy up to altitude $H$ of the coefficients $\kappa_{i}$ and of $R_{\mathrm{a}}$ from (A.6). The value of the gravitational acceleration at altitude $h$ is given by:

$$
g(h)=g^{0}\left(\frac{R_{\mathrm{T}}}{R_{\mathrm{T}}+h}\right)^{2}
$$

where $g^{0}$ is the value of $g$ at sea level and $R_{\mathrm{T}}$ is the conventional radius of the Earth. We considered $R_{\mathrm{T}}=6378.388 \mathrm{~km}$ and $h=9.80665 \mathrm{~m} / \mathrm{s}^{2}$. We evaluate numerically the integral from (6) for $h^{*}=0 \mathrm{~m}$ and $T^{*}$ varying between $273 \mathrm{~K}$ and $313 \mathrm{~K}$, using the model CIRA-61 [8]. It resulted an error inferior to $0.5 \%$ in case we used the constant value $g^{0}$ in place of $g(h)$. What we mentioned above allow the ratio $g / R_{\mathrm{a}}$ be removed from the integral of equation (6).

In any of the four thermal strata, the temperature $T_{k}(h)$ can be directly computed using (2) and the value $T_{k}^{0}$. In case the temperature varies linearly with altitude $(k=1$ or 3$)$ we have :

$$
\mathrm{d} T=a_{k} \mathrm{~d} h .
$$

Using (C.2) and (B.11), after computing (6) we have :

$$
F_{k}(h)=\left(1+w_{k}^{0}\right)^{\beta}\left[\frac{T(h)}{T_{k}^{0}}\right]^{n_{k}}
$$

where :

$$
n_{k}=-\frac{g^{0}}{a_{k} R_{\mathrm{a}}} .
$$

Remplacing (C.3) in (5) we obtain :

$$
p_{k}(h)=p_{k}^{0}\left[\frac{T(h)}{T_{k}^{0}}\right]^{n_{k}} M_{k}\left(h, T_{k}^{0}, w_{k}^{0}\right) .
$$

In (C.5) we used the notation :

$M_{k}\left(h, T_{k}^{0}, w_{k}^{0}\right)=B_{k}^{1}\left[1-\frac{B_{k}^{2} A_{k}(h)}{1+(\alpha+1) B_{k}^{2} A_{k}(h)}\right]$

where :

$$
\begin{gathered}
A_{k}(h)=\left(T_{k}(h) / T_{k}^{0}\right)^{\alpha n_{k}} \\
B_{k}^{1}=\left(1+w_{k}^{0}\right)^{\beta} \\
B_{k}^{2}=\beta w_{k}^{0}\left(1+w_{k}^{0}\right)^{\alpha \beta} .
\end{gathered}
$$

In case of a dry atmosphere, $w_{k}^{0} \rightarrow 0$, resulting $B_{k}^{1} \rightarrow 1$ and $B_{k}^{2} \rightarrow 0$ and finally $M_{k} \rightarrow 1$. In this situation the solution (C.5) tends to Laplace's classical solution. By means of equations (3) and (C.5) we found :

$$
w_{k}(h)=w_{k}^{0} A_{k}(h) M_{k}^{\alpha} .
$$

In case the temperature is constant in the stratum $k$ $(k=2$ or 4$)$, a simple calculation of (6) leads to :

$F_{k}(h)=\left(1+w_{k}^{0}\right)^{\beta} \exp \left[-\frac{g^{0}}{R_{\mathrm{a}} T_{k}^{0}}\left(h-h_{k-1}\right)\right]$.

Replacing (C.11) in (5) we obtain :

$$
\begin{aligned}
p_{k}(h)= & p_{k}^{0} \times \\
& \times \exp \left[-\frac{g_{0}}{R_{\mathrm{a}} T_{k}^{0}}\left(h-h_{k-1}\right)\right] N_{k}\left(h, T_{k}^{0}, w_{k}^{0}\right) .
\end{aligned}
$$


In (C.12) we noted :

$N_{k}\left(h, T_{k}^{0}, w_{k}^{0}\right)=B_{k}^{1}\left[1-\frac{B_{k}^{2} C_{k}(h)}{1+(\alpha+1) B_{k}^{2} C_{k}(h)}\right]$

where $B_{k}^{1}, B_{k}^{2}$, are given by (C.8) and (C.9) and :

$$
C_{k}(h)=\exp \left[-\frac{\alpha g^{0}}{R_{\mathrm{a}} T_{k}^{0}}\left(h-h_{k-1}\right)\right] \text {. }
$$

Using equations (3) and (C12) we found :

$$
w_{k}(h)=w_{k}^{0} C_{k}(h) N_{k}^{\alpha} .
$$

Examining the equations (C.5) and (C.12) we observe that pressure values can be determined by :

$$
p_{k}(h)=p_{k}^{0} \psi_{k}(h)
$$

where the functions $\psi_{k}(h)$ are :

$$
\psi_{k}(h)= \begin{cases}M_{k}\left[\frac{T(h)}{T_{k}^{0}}\right]^{n_{k}} & k=1 \text { or } 3 \\ N_{k} \exp \left[-\frac{g^{0}}{R_{\mathrm{a}} T_{k}^{0}}\left(h-h_{k-1}\right)\right] & k=2 \text { or } 4 .\end{cases}
$$

We verified the continuity of the functions $\psi_{k}$, which might have been affected by the approximations we used in solving the equation (B.8). From (C.16) we derive the continuity condition :

$$
\psi_{k}\left(h_{k-1}\right)=1 \text {. }
$$

Using (C.17), we obtain an equivalent form of (C.18) :

$$
\begin{gathered}
M_{k}\left(h_{k-1}\right)=1 \\
N_{k}\left(h_{k-1}\right)=1 .
\end{gathered}
$$

According to a previous remark, if $w_{k}^{0} \rightarrow 0$, then $B_{k}^{1} \rightarrow 1$ and $B_{k}^{2} \rightarrow 0$, resulting $M_{k} \rightarrow 1$ and $N_{k} \rightarrow 1$. Consequently, the continuity is better fulfilled at the bottom of higher layers $(k=2,3,4)$, where $w_{k}^{0}$ is smaller. For safety reasons we performed calculations at the bottom of the first atmospheric layer, where $w_{k}^{0}$ has the highest value. We considered $u^{*}=100 \%, \quad h^{*}=0 \mathrm{~m}, \quad p^{*}=1000 \mathrm{hPa} \quad$ and $T^{*}=273-313 \mathrm{~K}$. At worst, the values $M_{1}(0)$ and $N_{1}(0)$ differ from 1 only at the sixth significant digit. Equation (C.17) allows to compute the pressure $p_{k}(h)$ as a function of the ground value $p^{*}$ :

$$
p_{k}(h)=p^{*} \phi_{k}\left(h, h^{*}, T^{*}, w^{*}\right) .
$$

In (C.20) the function $\phi_{k}$ has the form :

$$
\phi_{k}(h)=\psi_{k}(h) \prod_{j=1}^{k-1} \psi_{j}\left(h_{j}\right)
$$

In the case $k=1$ we have :

$$
\phi_{1}(h)=\psi_{1}(h) \text {. }
$$

\section{Appendix D.}

The calculation of the integral from (1.b) is performed by decomposing the domain of definition into four subdomains, corresponding to equation (2) which define $T(h)$ :

$$
\int_{h^{*}}^{H} \frac{\kappa_{i}}{1+A w} \frac{p}{T} \mathrm{~d} h=\sum_{k=1}^{4} \int_{h_{k-1}}^{h_{k}} \frac{\kappa_{i}}{1+A w} \frac{p}{T} \mathrm{~d} h=\sum_{k=1}^{4} I_{i k} .
$$

In (D.1) we noted $h_{0}=h^{*}$. To estimate the integrals $I_{i k}$ we observe that the values of the paranthesis appearing in (C.6) and (C.13) are in fact equal to 1.

This situation is owed to the fact that the value of $B_{k}^{2}$ is at most of the order 0.001 and in troposphere the ratio $T_{1}(h) / T_{1}^{0}$, which is subunitary, is raised to a high power. In case $k=3$, when $T_{3}(h) / T_{3}^{0}$ is overunitary, we take into account that the value $w_{k}$ can be totally neglected within the respective domain of the atmosphere. Using these approximations it results that $M_{k}$ and $N_{k}$ are constant within each thermal stratum, having the value equal to $B_{k}^{1}$. Taking into account what we mentioned above, by using equations (2) and (C.5) we obtain for the layers 1 and 3 :

$$
I_{i k}=\frac{\kappa_{i} B_{k}^{1} p_{k}^{0}}{n_{k} a_{k}}\left(\psi_{k}\left(h_{k}\right)-1\right) \quad k=1 \text { or } 3 .
$$

In case of the layers 2 or 4 , by using equations (2) and (C.12) we obtain :

$$
I_{i k}=\frac{\kappa_{i} R_{\mathrm{a}} B_{k}^{1} p_{k}^{0}}{g^{0}}\left(1-\psi_{k}\left(h_{k}\right)\right) k=2 \text { or } 4 .
$$

We introduce the notations :

$\varphi_{k}\left(h_{k}\right)= \begin{cases}B_{k}^{1} \frac{\psi_{k}\left(h_{k}\right)-1}{n_{k} a_{k}} & k=1 \text { or } 3 \\ B_{k}^{\frac{R_{\mathrm{a}}\left(1-\psi_{k}\left(h_{k}\right)\right)}{g^{0}}} & k=2 \text { or } 4 .\end{cases}$ 
Taking into account of (C.21), the integral (D.1) In (D.5) the function $\theta_{g i}$ is given by : becomes :

$\int_{h^{*}}^{H} \frac{\kappa_{i}}{1+A w} \frac{p}{T} \mathrm{~d} h=\kappa_{i} p^{*} \theta_{g i}\left(h^{*}, T^{*}, w^{*}\right)$

$$
\boldsymbol{\theta}_{g i}=\sum_{k=1}^{4} \varphi_{k}\left(h_{k}\right) \phi_{k}\left(h_{k-1}\right) \text {. }
$$

To compute the integral from (1.a) we take into account equation (3). We have :

$$
\int_{h^{*}}^{H} \frac{A w}{1+A w} \frac{p}{T} \mathrm{~d} h=\sum_{k=1}^{4} \int_{h_{k-1}}^{h_{k}} \frac{A w_{k}^{0} p^{\alpha+1}}{\left(p_{k}^{0}\right)^{\alpha}+A w_{k}^{0} p^{\alpha}} \frac{\mathrm{d} h}{T}=\sum_{k=1}^{4} I_{\mathrm{w} k} .
$$

For $k=1$ or 3 we use (C.5) and we obtain

$$
I_{\mathrm{w} k}=\frac{A w_{k}^{0} p_{k}^{0}}{a_{k}} \int_{1}^{\frac{T_{k+1}^{0}}{T_{k}^{0}}} \frac{\left(T_{k}(h) / T_{k}^{0}\right)^{n_{k}(\alpha+1)-1} M_{k}^{\alpha+1}}{1+A w_{k}^{0}\left(T_{k}(h) / T_{k}^{0}\right)^{n_{k} \alpha} M_{k}^{\alpha}} \mathrm{d}\left(\frac{T_{k}(h)}{T_{k}^{0}}\right) .
$$

A similar reasoning to that from the beginning of the Appendix proves that the denominator from (D.8) can be considered as equal to unity and $M_{k} \approx B_{k}^{1}$. After performing the calculations we have :

$$
I_{\mathrm{w} k}=\frac{w_{k}^{0}\left(B_{k}^{1}\right)^{\alpha+1} A}{a_{k}(\alpha+1) n_{k}} p_{k}^{0}\left[\left(T_{k+1}^{0} / T_{k}^{0}\right)^{n_{k}(\alpha+1)}-1\right] k=1 \text { or } 3 .
$$

For $k=2$ or 4 the integral $I_{\mathrm{w} k}$ can be computed taking into account (C.12). The denominator is in fact equal to unity and $N_{k} \approx B_{k}^{1}$, because in the respective regions of the atmosphere the content of humidity is negligible. After performing the calculations we obtain :

$$
I_{\mathrm{w} k}=\frac{w_{k}^{0}\left(B_{k}^{1}\right)^{\alpha+1} A R_{\mathrm{a}}}{g^{0}(\alpha+1)} p_{k}^{0}\left[1-\exp \left(-\frac{g^{0}(\alpha+1)}{R_{\mathrm{a}} T_{k}^{0}}\left(h_{k}-h_{k-1}\right)\right)\right] k=2 \text { or } 4 .
$$

It can be remarked that (D.9) and (D.10) can be expressed under the form :

$$
I_{\mathrm{w} k}=A p_{k}^{0} \omega_{k}
$$

where :

$\omega_{k}\left(h_{k}\right)=\left\{\begin{array}{l}\frac{w_{k}^{0}\left(B_{k}^{1}\right)^{\alpha+1}}{a_{k} n_{k}(\alpha+1)}\left[\left(T_{k+1}^{0} / T_{k}^{0}\right)^{n_{k}(\alpha+1)}-1\right] \quad k=1 \text { or } 3 \\ \frac{R_{\mathrm{a}} w_{k}^{0}\left(B_{k}^{1}\right)^{\alpha+1}}{g^{0}(\alpha+1)}\left\{1-\exp \left[-\frac{g^{0}(\alpha+1)}{R_{\mathrm{a}} T_{k}^{0}}\left(h_{k}-h_{k-1}\right)\right]\right\} \quad k=2 \text { or } 4 .\end{array}\right.$

Taking into account (C.20) we can estimate the integral (D.7) :

$$
\int_{h^{*}}^{H} \frac{A w}{1+A w} \frac{p}{T} \mathrm{~d} h=A p^{*} \theta_{\mathrm{w}}\left(h^{*}, T^{*}, w^{*}\right) .
$$

The function $\theta_{\mathrm{w}}$ from (D.13) has the form :

$$
\theta_{\mathrm{w}}=\sum_{k=1}^{4} \omega_{k}\left(h_{k}\right) \phi_{k}\left(h_{k-1}\right) \text {. }
$$

The mass of water, $m_{\mathrm{w}}$, having the density $\rho_{\mathrm{w}}\left(T^{*}\right)$, occupies the volume $V_{\mathrm{w}}$ :

$$
V_{\mathrm{w}}=\frac{S A p^{*} \theta_{\mathrm{w}}}{R_{\mathrm{w}} \rho_{\mathrm{w}}\left(T^{*}\right)} .
$$

The volume $V_{\mathrm{w}}$ corresponds to a cylinder of height $h_{\mathrm{w}}$ and surface area $S$. Then, it results :

$$
h_{\mathrm{w}}=\frac{A p^{*} \theta_{\mathrm{w}}\left(p^{*}, T^{*}, w^{*}\right)}{R_{\mathrm{w}} \rho_{\mathrm{w}}\left(T^{*}\right)} .
$$

Similarly, we consider the mass $m_{g i}$ of gas $i$ be contained in the volume $V_{g i}$. It results :

$$
V_{g i}=\frac{m_{g i} R_{i} T^{*}}{p^{*}}=S \kappa_{i} T^{*} \theta_{g i} .
$$

We assume the volume $V_{g i}$ as a cylinder of height $h_{g i}$ and surface area $S$. We have :

$$
h_{g i}=\kappa_{i} T^{*} \theta_{g i}\left(p^{*}, T^{*}, w^{*}\right) .
$$




\section{References}

[1] MAY, B. R. et al., Handbook of methods of estimating solar radiation, Swedish Council for Building Research (Stockholm, Sweden, Nov. 1984) p. 432.

[2] BENER, P., ibidem, p. 47-84.

[3] Davies, J. A., ibidem, p. 84-101.

[4] HANN, J., Lehrbuch der Meteorologie, Tauchnitz, Leipzig, p. 225, 1901 ; quoted in reference [1]

[5] Paltridge, G. W., Platt, C. M. R., Radiative processes in meteorology and climatology, Developments in Atmospheric Science, § 5 (Elsevier, New York, 1976) p. 318.

[6] GATES, D. M., Energy exchange in the biosphere (Harper and Row, New York) 1962.

[7] Smith, W. L., J. Appl. Meteor. 5 (1966) 726-727.

[8] Dinulescu, N. I., Refractia Astronomică, Ed. Academiei RSR, Bucuresti, 1967.

[9] KING, R., Buckius, R. O., Solar Energy 22 (1979) 297-301.

[10] VoINESCU, V. et al., Indrumătorul instalatorilor, Ed. Tehnica (Bucuresti) 1964.

[11] Barbaro, S. et al., Solar Energy 22 (1979) 225-228.

[12] Perrin De Brichambaut, Ch., Estimation du rayonnement solaire, Publication du secrétariat d'État auprès du Ministère de l'Équipement et de l'Aménagement du Territoire, Direction de la Météorologie, Janvier 1978.

[13] Lacis, A. A., Hansen, J. E., J. Atmos. Sci. 31 (1974) 118-133.

[14] Goody, M., Atmospheric Radiation (London, University Press, 1964) p. 436.

[15] Somerville, R. C. J. et al., J. Atmos. Sci. 31 (1974) 84-117.

[16] Moeller, F., Long wave radiation, Compendium of Meteorology, Boston, Amer. Meteor. Soc. (1951) p. 39-49.

[17] Kaplan, L. D., J. Meteor. 9 (1952) 1-12.

[18] Paltridge, G. W., J. Atmos. Sci. 30 (1973) 156-160.

[19] Yамамото, G., J. Atmos. Sci. 19 (1962) 182-188.

[20] McDonald, J. E., J. Meteor. 17 (1960) 319-328.

[21] RoMAN, P., Introducere in fizică poluarii fluidelor, Ed. Stiintifica si Enciclopedică (Bucuresti) 1980.

[22] Ursu, P. et al., Protejarea aerului atmosferic, Ed. Tehnică (Bucuresti) 1978.

[23] Crosby, D. C. et al., J. Atmos. Sci. 30 (1973) 141144.

[24] Smoleanski, M. L., Tabele de integrale nedefinite, Ed. Tehnică, Bucuresti, 1972 (from Russian).

[25] DinH, H., Rev. Gen. de Thermique 59 (1966) 1081. 